\title{
De Menino À Sujeito-Homem: \\ Um Relato De Experiência
}

From Boy to Guy-Man:

A Report of Experience

\section{De niño a hombre-hombre: \\ Un informe de experiencia}

Rubiana Nascimento Viana ${ }^{1}$

\begin{abstract}
RESUMO
O seguinte trabalho apresenta análises que objetivam relatar uma experiência de estágio curricular obrigatório em psicologia, em uma instituição para cumprimento de medida socioeducativa direcionada à jovens em conflito com a lei, também usuários de um serviço de saúde mental. Considerando os tensionamentos produzidos ao longo deste período, bem como os atravessamentos raciais e socioeconômicos que antecedem a minha chegada a este lugar e que se desenrolam também ao longo das intervenções, tais análises produzem um analisador visceral: O silêncio. E é a partir deste que desenvolvo o relato, retomando a narrativa em uma tentativa de esmiuçar os fatores históricos e sociais que aproximam meu corpo ao corpo dos jovens ali encarcerados, incluindo em minhas análises as perspectivas construídas em função dos recortes produzidos em mim e nos sujeitos, colocando-me também em questão e valendo-me do método cartográfico de Deleuze e Guattari (1995) e da Necropolítica de Mbembe (2016).
\end{abstract}

PALAVRAS-CHAVE: Psicologia, racismo, socioeducação, cartografia, necropolítica.

\section{ABSTRACT}

The following work presents analyzes that aim to report an experience of compulsory curricular traineeship in psychology, in an institution to comply with socioeducative measure directed at young people in conflict with the law, also users of a mental health service. Considering the tensions produced during this period, as well as the racial and socioeconomic crossings that precede my arrival to this place and that also unfold throughout the interventions, such analyzes produce a visceral analyzer: Silence. And it is from this that I develop this account, resuming the narrative in an attempt to scrutinize the historical and social factors that bring my body closer to the body of the young people incarcerated, including in my analyzes the perspectives built on the cuts produced in me and in the subjects, putting me also in question and drawing on the cartographic method of Deleuze and Guattari (1995) and the Necropolitics of Mbembe (2016).

KEYWORDS: Psychology, racism, socioeducation, cartography, necropoly.

\section{RESUMEN}

El siguiente trabajo presenta análisis que apuntan a informar una experiencia de entrenamiento curricular

Submetido em: 24/07/2019 Aceito em: 14/08/2019 Publicado em: 31/08/2019. 
obligatorio en psicología, en una institución para cumplir con medidas socioeducativas dirigidas a jóvenes en conflicto con la ley, también usuarios de un servicio de salud mental. Teniendo en cuenta las tensiones producidas durante este período, así como los cruces raciales y socioeconómicos que preceden a mi llegada a este lugar y que también se desarrollan a lo largo de las intervenciones, dichos análisis producen un analizador visceral: el silencio. Y es a partir de esto que desarrollar la historia, retomando la historia en un intento de examinar los factores históricos y sociales que traen a mi cuerpo a cuerpo de allí encarcelados los jóvenes, incluso en mi análisis de las perspectivas construidas sobre la base de los recortes producidos en mí y Temas, poniéndome también en cuestión y recurriendo al método cartográfico de Deleuze y Guattari (1995) y Necropolitica de Mbembe (2016).

PALABRAS CLAVE: Psicología, racismo, socioeducación, cartografía, necropolía.

\section{INTRODUÇÃO}

A jornada que me leva a esses escritos é anterior a qualquer intervenção prática e institucional que aqui porventura será posta em xeque. Ao longo da trajetória do estágio na instituição para cumprimento de medida socioeducativa, tornou-se impossível não falar dos sujeitos em questão sem os devidos atravessamentos de ser quem se é: Mulher, negra, periférica, mãe jovem e solteira. $\mathrm{O}$ que de início me impulsionava à neutralidade ou imparcialidade quase empírica de uma pesquisadora, que se reconhecia há até pouco tempo mais nas ciências sociais do que na psicologia em si, se revelou cada vez mais um espelho, que refletia para além da minha própria face. Mostrava o quanto a minha história se aproximava da história daqueles sujeitos, e o quanto esta se repete em tantos outros pares. Fugir deste fato não era somente impossível como também não recomendado. Ao compreender isto, retomo àquilo que Lewin em sua psicologia social, Guattari em sua análise institucional e muitos outros depois destes já haviam demonstrado: Que “(...) a recusa da neutralidade do analista/pesquisador procura romper (...) as barreiras entre o sujeito que conhece e o objeto a ser conhecido" (PASSOS e BENEVIDES, 2000, p. 73), o que introduz outras perspectivas acerca dos sujeitos em questão e reserva para o pesquisador um outro lugar. Em um país onde até 2011, 5,5 milhões de crianças não possuíam o nome do pai no registro civil ${ }^{2}$; onde $54,9 \%$ da população se declara negra ou parda ${ }^{3}$; onde os negros representam três quartos da população pobre ${ }^{4}$ e $72 \%$ da população carcerária ${ }^{5}$, parece que contar essas histórias é tão somente tornar evidente os fatos mais reais e presentes no cotidiano e na vida comum de cada brasileiro, que se naturalizam e quase não se tornam mais visíveis. É falar de algo tão meu e tão íntimo, que determinou tanto quem sou, que já nem percebia. A chibata que já não machuca a pele anestesiada, ao passo que as feridas em si não cicatrizam. Fazer disso um relato de experiência é dizer de alguém que foi tão construído pelos estigmas presentes na

\footnotetext{
${ }^{2}$ Dados do Conselho Nacional de Justiça (CNJ), com base no Censo Escolar de 2011.

${ }^{3}$ Pesquisa Nacional por Amostra de Domicílios Contínua 2016, IBGE.

${ }^{4}$ Idem.

${ }^{5}$ Dados do Infopen, o Sistema Integrado de Informações Penitenciárias, divulgados pelo Ministério da Justiça.
} 


\section{Revista Docência e Cibercultura}

sociedade quanto os próprios citados. É uma pesquisadora no limbo do dentro-fora, que consegue enxergar as circunstâncias e a conjuntura de todo um sistema opressor, mas que ainda assim está submetida a ele. As análises que se apresentam só foram potencializadas quando entendi que também compunha este corpo. Baremblitt (2002) diz que uma análise institucional torna-se possível somente a partir da análise de implicações, que o mesmo determina enquanto os atravessamentos que perpassam a equipe interventora ainda que inconsciente dos efeitos que produz naquela instituição e em si própria, o que justifica a reciprocidade do processo analítico e da experiência que vivi.

Eu sou negra, nasci no interior do Rio. Minha mãe tem sua carteira assinada como auxiliar de serviços gerais desde o ano 2000 e há 19 anos recebe o salário mínimo permitido por lei, assim como meu pai. Fui bolsista metade da minha vida e na graduação, cotista. Toda a minha renda mensal ao longo deste período veio de programas do governo. Fui mãe aos 17 anos, e desde o nascimento do meu filho o crio por conta própria, com auxílio somente dos meus pais. Este poderia ser o relato de outras tantas mulheres, mas ainda é o meu. Particularmente, o relato do meu filho será extremamente próximo ao de diversos jovens em conflito com a lei e asilados na instituição socioeducativa analisada. Há uma linha invisível e tênue que me separa deles, um sútil fato que marca as nossas vidas enquanto sujeitos, e que me atravessou de uma forma diferente: A violência.

Reconheço os caminhos que me levaram à universidade e os levaram à cadeia, como dizem. Donzelot (1980) já esboçava em seus escritos como a ideia de incapacidade da mãe miserável em fazer de seus filhos sujeitos moralmente capazes de conviver em sociedade foi construída pelo Estado para dar conta dos problemas sociais produzidos pelas desigualdades; bem como a subdivisão esmiuçada por Coimbra (2001), da população pobre entre os viciosos e os funcionais - aqueles que ofertam sua mão-de-obra em trabalhos ditos dignos, apesar de extremamente exploratórios e mal remunerados, mas que internalizam com maior facilidade a lógica estrutural burguesa de família e costumes. Na minha tenra infância, mesmo perambulando por territórios de extrema violência, eu nunca vi um corpo sangrar na minha frente. Eu ouvia os meus pares anunciarem da violência, mas ela nunca bateu de fato na minha porta. Entendo o contexto que me construiu, sei que graças a ele alcancei voo por espaços nunca antes explorados por meus semelhantes. Minha mãe não é viciosa, e não possui filhos asilados. Conheço jovens asilados filhos de mães iguais a minha. Pude observar com meus próprios olhos que, longe de pobres viciosos ou funcionais, em verdade, somos sujeitos, alcançados em maior ou menor grau pelo poder público, ora assistencialista, ora 


\section{Revista Docência e Cibercultura}

punitivista, mas de maneira geral, tombados pelas práticas genocidas ${ }^{6}$ que objetivam uma política sistêmica de reprodução de desigualdades

A estrada que leva até a unidade que descrevo nestas análises é de um asfalto gasto e danificado, onde até as lombadas possuem buracos. A vista se alterna entre matas densas e fazendas, e de vez em quando alguns casebres. O trabalho da equipe a qual estava inserida já acontecia desde o começo do ano, com outros profissionais do $\mathrm{CAPSi}^{7}$, e agora estariam presentes as duas novas estagiárias, dentre estas, eu. Anterior à nossa chegada, havia uma psicóloga que seria nossa supervisora de estágio no campo, uma enfermeira do CAPSi e outra estagiária, mais antiga.

No dia 9 de abril de 2018 estive no meu respectivo campo de estágio pela primeira vez. É um lugar onde raramente o celular consegue algum sinal, o que por vezes me angustiou, especialmente porque me fazia sentir como alguém a parte, separada do mundo, o que soa intencional não só para os internos, mas também para os funcionários. Talvez faça mais sentido se entendermos que o efetivo de funcionários é mínimo perto da quantidade de jovens ali institucionalizados. A intenção é de fato produzir medo, e o sentimento mais potente e mais próximo ao medo é o ódio, cujo produto final, a violência, dita em muitos momentos as relações por ali estabelecidas. Vera Malaguti expôs em seus escritos a forma como a produção imaginária do medo se tornou uma via para a construção do caráter autoritário das estratégias de controle social no Brasil (SILVA, 2015) ao afirmar que "a hegemonia conservadora na nossa formação social trabalha a difusão do medo como mecanismo indutor de tomadas de posição estratégicas seja no campo econômico, político ou social" (MALAGUTI apud SILVA, 2015). Além disso, a autora estabelece uma "adesão subjetiva à barbárie", resultante de uma cultura punitivista produzida à partir do sentimento de medo inculcado nos sujeitos que é, em si, resultado final de uma produção imagética, midiática e sociopolítica. Em outras palavras, quanto mais medo os agentes penais sentem, mais expressam este sentimento através da violência, da opressão e do controle dos corpos.

\footnotetext{
${ }^{6}$ Por genocídio, pela definição da ONU (1948), entende-se quaisquer dos atos abaixo relacionados, cometidos com a intenção de destruir, total ou parcialmente, um grupo nacional, étnico, racial, ou religioso, tais como: (a) assassinato de membros do grupo; (b) causar danos à integridade física ou mental de membros do grupo; (c) impor deliberadamente ao grupo condições de vida que possam causar sua destruição física total ou parcial; (d) impor medidas que impeçam a reprodução física dos membros do grupo; (e) transferir à força crianças de um grupo para outro (...). Genocídio é uma forma de violência complexa; o efeito de um conjunto de práticas cotidianas baseado no desejo de eliminação, ou de afastamento, do outro e por isso consentindo, mesmo que silenciosamente, a sua eliminação. Embora a explicação do genocídio não possa ser reduzida ao desejo de destruição do outro, não pode operar sem ele. (VERGNE et. al., 2015, p, 517.).

${ }^{7}$ Sigla para Centro e Atenção Psicossocial Infantil.
} 


\begin{abstract}
A adesão subjetiva à barbárie seria efeito de uma sociedade fascinada e, ao mesmo tempo, aterrorizada pelo excesso de violência veiculada pelas mass media que não cansam de isentar os governos liberais de suas responsabilidades sociais e políticas quando apontam incessantemente a criminalidade, ou melhor, os criminosos (preferencialmente de pele preta e com status de pobre), como modo de individualizar a causa de todos os males contemporâneos, sem fazer qualquer relação com os efeitos próprios do neoliberalismo e com a seletividade de um direito penal do inimigo. (ZAFFARONI apud SILVA, 2015, p. 66).
\end{abstract}

O dispositivo em questão se encontra alocado em um terreno similar a um morro, bem no topo. Ao chegarmos, somos direcionadas para o setor de saúde assim que chegamos à instituição, onde nos organizamos em salas separadas. Em uma das salas fica a enfermeira, na outra a estagiária mais antiga, enquanto a psicóloga supervisora, a estagiária mais recente e eu compartilhamos uma mesma sala. Os atendimentos eram feitos em um modelo clínico, onde dispúnhamos de nossa escuta e acolhimento para as demandas emergentes, e nos casos em que avaliássemos necessário, disponibilizaríamos um encaminhamento para consulta com psiquiatra no CAPSi, o que resultaria uma possível intervenção medicamentosa através de psicofármacos ${ }^{8}$. Anterior ao nosso atendimento, os jovens eram selecionados pela assistente social da pasta de Saúde Mental da instituição, através de solicitações deles próprios.

O modelo de atendimento ao qual estávamos condicionadas seguiria nesse formato pelos meses seguintes, o que me causou incômodo por muito tempo. Primeiro pelo atendimento ser clínico-individual, quando as demandas que surgiam na maioria dos encontros não somente tinham suas origens no âmbito sociopolítico, como também eram comuns à quase todos os jovens daquela instituição. $O$ trabalho restrito ao momento clínico passava a sensação de uma intervenção fragmentada, ou parcialmente cega, e no fim das contas, ineficaz. Além disso, o atendimento em trio o qual fiz parte em mais da metade do tempo de vigência do trabalho não me agrava, pois constituía, a meu ver, uma dicotomia 3 contra 1, que constrangia em muitos momentos a mim e ao menino que se colocava nesse lugar. No entanto, compreendo que para aquele momento, este tipo de atendimento fez-se crucial, uma vez que fora ali onde os vínculos surgiram, e que aos poucos, nosso trabalho foi se consolidando. Outro ponto é que esta foi a minha primeira experiência de acolhimento clínico, meu primeiro estágio curricular, e eu certamente não daria conta disto completamente sozinha, dadas as muitas questões que suscitavam nestes encontros. O que não pode de forma alguma ser deixado do lado de fora do consultório do psicólogo clínico, como afirma Benevides (2005), é a dimensão política que circunscreve todos os sujeitos, e que marcava de maneira incisiva aqueles que atendíamos na instituição. A autora preconiza em seus estudos as práticas que a psicologia desenvolve em

\footnotetext{
${ }^{8}$ Medicações com substâncias psicotrópicas “que atuam sobre o nosso cérebro, alterando de alguma maneira o nosso psiquismo (...) podem ser classificadas em três grupos, de acordo com a atividade que exercem junto ao nosso cérebro: Depressores da Atividade do SNC; Estimulantes da Atividade do SNC; Perturbadores da Atividade do SNC.” (CEBRID, 2013).
} 
seu modelo clínico-individual que subdividem os sujeitos, condicionando as análises ao longo das sessões somente à esfera subjetiva e mantendo-se aquém às dimensões que também se manifestam no momento clínico, retornando a uma psicologia que se sustenta no pressuposto de que política e ciência não se misturam.

O efeito-despolitização neste tipo de análise é notório, posto que as práticas psi passam a se ocupar de sujeitos abstratos, abstraídos/alienados de seus contextos e tomam suas expressões existenciais como produtos/dados a serem reconhecidos em universais apriorísticos. Digo despolitização para marcar o lugar exterior, separado, em que a política, em suas mais variadas formas, é lançada quando se trata da análise das questões subjetivas. Entretanto, o mais correto seria dizer que aí também há a produção de uma certa política: aquela que coloca de um lado a macropolítica e, de outro, a micropolítica; de um lado, o Sistema Único de Saúde como dever do Estado e direito dos cidadãos, como conquista garantida pela lei, pela Constituição e, de outro, os processos de produção de subjetividade. (BENEVIDES, 2005, p.22)

É importante, por fim, ressaltar que, em verdade, a problemática acerca dos atendimentos realizados no decorrer desta experiência não está no fato destes serem efetivados individualmente, mas em se demarcarem enquanto individualizantes ou não; e definir isto é, portanto, crucial para qualquer análise que se desenrole.

Intrínseco aos meus contrapontos em relação ao exercício clínico da psicologia - os quais temo quando reduzem as questões macropolíticas que se apresentam à esfera subjetiva - é o próprio papel do psicólogo na sociedade. Demorei pouco tempo para descobrir o lugar do psicólogo no mundo, mas para além de saber disso, não hesitar em acreditar foi também vital para o meu desenvolvimento tanto acadêmico quanto subjetivo. Em verdade, ao passo que logo nos primeiros contatos com a ideia de uma psicologia que pode se desenvolver em quase todos os espaços tive minhas dúvidas desfeitas acerca das suas múltiplas faces, demorei mais tempo para compreender que compartilhamos muitos destes espaços com outras áreas do saber. Passei um longo tempo acreditando que essa minha sede - que ainda não descobri de quê - era de algo muito mais próximo da antropologia do que da psicologia. Ao longo da graduação tive muitas oportunidades de me envolver em atividades do curso de ciências sociais do meu campus universitário, o que me deixou ainda mais angustiada em relação à minha própria práxis e ao meu lugar na psicologia. Foi necessário esforço de muitos colegas, aos quais tenho imenso apreço, e muita leitura para entender que até mesmo esse escopo fluído, parecidíssimo com a sociologia cabe na psicologia, e que esta não é nem neutra e nem apolítica, assim como tudo na vida em sociedade. Encontrei o respaldo para minha existência singular na cartografia de Deleuze e Guattari e na genealogia de Foucault, metodologias que orientam pesquisas no campo de saber psicológico e surgem como uma possibilidade de reinventar tal prática diante da metodologia tradicional presente até então (ZAMBENEDETTI; DA SILVA, 2011). Já que aquilo que descrevo em meus escritos obedece a uma lógica temporal que foge à norma padrão da historicidade - quando me 
proponho a relatar uma experiência passada que ainda se dá, que encontra-se ainda em ato, escrita enquanto vivida - o método cartográfico serviu-me muito bem, não somente para possibilitar um relato pautado em uma intervenção, mas também para ampliar minha capacidade de visualizar tudo que poderia escrever, acreditando nas potências das muitas vicissitudes que ali se deram, pois:

A cartografia (...) é tomada como um mapa em constante processo de produção, instaurando um processo de experimentação contínua capaz de criar novas coordenadas de leitura da realidade, criando uma ruptura permanente dos equilíbrios estabelecidos. Com este procedimento cartográfico colocam-se em questão as hierarquias e fronteiras que dividem os campos de conhecimento e propõe-se uma recriação permanente do campo investigado. (ZAMBENEDETTI; DA SILVA, 2011, p. 457).

Para além de orientar pesquisas, a cartografia torna possível um pesquisador capaz de compreender que suas capturas e rupturas são também parte do processo e passíveis de leitura, uma vez que a nossa implicação consolida o pressuposto que nos leva até o campo. Cartografar ao construir meus escritos é também construir parte da minha subjetividade.

$\mathrm{O}$ ano anterior à minha entrada neste dispositivo foi bastante traumático. Um ano violento, como todos os outros, mas em que me vi muito mais implicada, tanto pela militância quanto pelos afetos, nos casos de violência do Estado contra uma classe e uma cor. Foi quando não só me dei conta do quão real é o genocídio da população negra e pobre no Brasil, mas que me envolvi emocionalmente de tal forma com cada caso anunciado, que saber deles me machucava em algum lugar que sequer sei descrever. Eu sentia que era comigo, como se fosse um pedaço meu; ou ainda, que o meu corpo é similar a estes os quais o Estado definiu matáveis. Entre janeiro e novembro de 2017, 1.035 pessoas foram mortas pela polícia militar do estado do Rio e Janeiro ${ }^{9}$. De janeiro de 2016 até março de 2017, 9 em cada 10 mortos pela polícia no Rio eram negros ou pardos; e das 1227 pessoas mortas naquele ano, metade tinha até 29 anos e 108 possuíam 18 anos ou menos ${ }^{10}$. Contudo, diante de todos esses números, meu refúgio foi afastar-me, esquecer os nomes, os rostos e tudo que me recordasse essa minha dor. Afastar-me de todas as fake news que surgiam para justificar as mortes, manchando o nome dos que se foram demonstrando que vivemos sob a égide de um Estado que, ao se assumir responsável pelas vidas da população que o constitui, empenha-se em decidir quem vive e quem morre, naturalizando os corpos alvejados e tornando-os parte do cotidiano da vida em sociedade.

A atual política criminal da chamada 'guerra contra as drogas' evidentemente ofende mais à saúde pública que à própria circulação destas substâncias. Se é verdade que o direito busca, ao reprimir as condutas descritas como tráfico de

\footnotetext{
${ }^{9}$ Dados do ISP - Instituto de Segurança Pública de 2017.

${ }^{10}$ Dados obtidos pelo UOL através da Lei de Acesso à Informação e cedidos pelo ISP.
} 
drogas, proteger 'o estado em que o organismo social exerce normalmente todas as suas funções' (saúde pública), como entender que a violência criada pela guerra contra o tráfico no Rio de Janeiro tenha atingido níveis de homicídio superior aos da guerra de Bush no Iraque? (D’ELIA, 2008, p. 37).

Em verdade, tal como preconiza o autor, a política de segurança pública implantada pelo Estado para o enfrentamento do comércio ilícito de drogas aproximasse de uma estratégia de guerra não somente pela sua letalidade bélica, mas também pelos moldes estruturais e sistêmicos através dos quais ela se propaga. A criação de um inimigo da nação que precisa ser combatido a qualquer custo, baseado na ideia de um inimigo interno que possui origens ditatoriais - outrora os comunistas e hoje, os traficantes - cujo extermínio se justifica e a inflação midiática de um estado de sítio o qual somente ouvimos falar (COIMBRA, 2001) são aspectos que também compõem a política de enfrentamento que objetiva, para além de um suposto controle da violência e combate ao mal, o controle social.

Em minha argumentação, relaciono a noção de Biopoder de Foucault a dois outros
conceitos: o estado de exceção e o estado de sítio. Examino essas trajetórias pelas
quais o estado de exceção e a relação de inimizade tornaram-se a base normativa do
direito de matar. Em tais instâncias, o poder (e não necessariamente o poder estatal)
continuamente se refere e apela à exceção, emergência e a uma noção ficcional do
inimigo. Ele também trabalha para produzir semelhantes exceção, emergência e
inimigo ficcional. Em outras palavras, a questão é: Qual é, nesses sistemas, a
relação entre política e morte que só pode funcionar em um estado de emergência?
Na formulação de Foucault, o biopoder parece funcionar mediante a divisão entre as
pessoas que devem viver e as que devem morrer. Operando com base em uma
divisão entre os vivos e os mortos, tal poder se define em relação a um campo
biológico - do qual toma o controle e no qual se inscreve. Esse controle pressupõe a
distribuição da espécie humana em grupos, a subdivisão da população em subgrupos
e o estabelecimento de uma cesura biológica entre uns e outros. Isso é o que
Foucault rotula com o termo (aparentemente familiar) "racismo". (MBEMBE, 2016,
p. 128)

De fato, a base desta cadeia, a essência deste projeto, é a separação da sociedade brasileira à partir dos aspectos raciais e sociais. Não por acaso, as desigualdades que fundamentam nosso projeto de nação se pautam em prerrogativas cujo produto final são os becos e as favelas pretas e pardas - lugar da guerra às drogas - onde o "racismo é acima de tudo uma tecnologia destinada a permitir o exercício do Biopoder, 'aquele velho direito soberano de morte'." (MBEMBE, 2016, p. 128).

O "estado de sítio" em si é uma instituição militar. Ele permite uma modalidade de crime que não faz distinção entre o inimigo interno e o externo. Populações inteiras são o alvo do soberano. As vilas e cidades sitiadas são cercadas e isoladas do mundo. O cotidiano é militarizado. É outorgada liberdade aos comandantes militares locais para usar seus próprios critérios sobre quando e em quem atirar. O deslocamento entre células territoriais requer autorizações formais. Instituições civis locais são sistematicamente destruídas. A população sitiada é privada de seus meios de renda. Às execuções a céu aberto somam-se matanças invisíveis. (MBEMBE, 2016, p. 137) 
Quando traz a noção de Necropolítica e Necropoder, fazendo contraponto ao Biopoder de Foucault, Achile Mbembe (2016) expõe enquanto exemplo desse Estado, que faz morrer populações inteiras através de amarras imagéticas e ideológicas, os conflitos na Palestina, na África e na Alemanha nazista. Lugares que revelam práticas abomináveis, mas que quando se repetem diante de nossos narizes, revelam o quanto estamos enquanto sociedade civil também presos às narrativas do controle social.

Contabilizando ao todo, estive ao longo de sete meses intercalando as minhas segundas-feiras entre tardes - que se estendiam até após a alvorada na maior parte das vezes - atendendo os jovens na instituição, e manhãs em que os recebíamos no CAPSi para o atendimento com o psiquiatra, seguindo o encaminhamento dado após o primeiro encontro no dispositivo onde estavam asilados. Com pausas que se davam somente nos feriados e ignorando recessos escolares, construí um diário de campo extenso que inclui escritos e mensagens de voz, das quais poderia extrair uma infinidade de material bruto passível de análises e análises. No entanto, minha implicação hoje me direciona para um paradigma específico, que me vincula àqueles sujeitos de maneira particular, diferente daqueles que me acompanhavam no desenvolvimento deste trabalho.

\section{O sujeito-homem e a morte em vida}

Apesar de este trabalho representar o relato de uma experiência que tive há meses, não posso caracterizá-lo como uma genealogia ${ }^{11}$. Eu cartografo porque escrevo enquanto vivo como já disse antes. Por meses, ansiei pelo dia em que escreveria o capítulo que ganhou nome antes de ganhar corpo. Para esta seção guardei minhas questões mais latentes, aquelas que pulsavam mais na emoção do que na razão, pegando algo abstrato e moldando, dando nome e corpo. No entanto, jamais imaginei que quando esse dia chegasse, eu estaria tão atormentada pela minha negritude.

Foram para estes parágrafos que eu reservei o relato da minha experiência em si, na sua essência. Foi aqui que eu planejei trazer as cenas do cotidiano da instituição que me impulsionaram a escrever. Há oito meses eu acreditava que as minhas 40 páginas de diário de campo dariam vida à minha monografia. Hoje eu sou menos ambiciosa. Em verdade, acredito que ainda não seja sobre ambição: A quem serve estes escritos? Esta é a questão chave deste trabalho. As pessoas as quais direciono este trabalho têm cor, classe social e um lugar préestabelecido no mundo que nos é dado antes mesmo de sermos concebidos. Das 40 páginas do meu diário de campo arrisco dizer que poucos parágrafos causariam nessas pessoas o impacto que busco, porque não é estranho a elas e nem a mim, isto é parte do nosso mundo, é

\footnotetext{
${ }^{11}$ Método genealógico de Foucault (ZAMBENETTI, 2011).
} 
parte do que somos e vivemos. Ao longo do século XIX e até meados do século XX existiam por toda Europa e também nos EUA algumas vilas e aldeias, compostas por negros de diversas etnias do continente africano, que eram expostos, muitas vezes entre animais, em lugares conhecidos como zoológicos humanos. Viviam sob condições precárias e eram observados pelos olhares curiosos dos europeus, que tentavam compreender ou julgar seu modo de vida e seu comportamento, trazendo um pedacinho da organização tribal e primitiva em que se encontravam para seu território civilizado. Os registros nos dizem de zoológicos humanos que exibiam nativos de quase todos os continentes - que não o europeu - incluindo nativos da América e da Austrália. Quando o último destes espaços de diversão familiar fechou as portas, na Bélgica, encontrava-se lá uma família congolesa enjaulada. O ano era 1958, 61 anos atrás ${ }^{12}$. Eu definitivamente não quero que a minha monografia atraia os olhares curiosos, ou que a instituição a que me refiro seja um zoológico humano. De todos os meus medos, talvez o que eu mais abomine em relação a estes escritos é torná-lo palatável de mais para alcançar seu destinatário.

Dito isso, me atenho às duas questões que circunscrevem as cenas que analisarei. A primeira delas diz sobre o meu silêncio. Todo meu estágio foi composto por uma gama de momentos os quais pouco pude intervir, e minhas análises buscam sanar a angústia gerada pelo "o que eu poderia ter feito". Os meus relatos tentam dar voz ao meu não posicionamento, que se alternava entre minha escolha por não falar e os silenciamentos. A segunda questão que me leva a escrever sobre a minha experiência neste referido estágio é o fato de eu discordar dele. Em diversos momentos eu entendi que a abordagem àqueles aos quais dirigíamos o nosso trabalho não era a mais adequada, e isso culminava no silencio anteriormente citado de duas formas: De início, eu compreendia que a minha perspectiva acerca daquilo que se passava, durante a nossa intervenção, era certamente atravessada pelas minhas vivências tanto sociais quanto da minha trajetória acadêmica, onde me envolvia com leituras e estudos acerca das populações sob um ponto de vista mais coletivo e menos individualizante - como na sociologia e na antropologia, no serviço social e na psicologia comunitária. Com isso, eu entendia que a minha discordância era um equívoco, uma vez que no início os trabalhos eram realizados através de atendimentos psicológicos individuais. Nestes momentos, ora eu escolhia me calar por entender meu erro, ora eu entendia que meu posicionamento não era relevante para aquela cena, e me sentia calada. Posteriormente, quando os trabalhos passaram a ser realizados através de intervenções grupais, eu compreendi que a minha perspectiva atravessada possuía sua importância naquele lugar, mas que diante dos contrapontos encontrados na minha própria equipe, talvez aquele não fosse $o$ momento ideal para apresenta-la. Diante disso, escolhi guardar tanto as experiências quanto a minha perspectiva para as análises que farei ao longo deste trabalho.

\footnotetext{
${ }^{12}$ Dados do Observatório do Terceiro Setor.
} 
Gosto do que Audre Lorde (1977) diz em "Transformação do Silêncio em Linguagem de Ação", escritos sobre visibilidade, quando afirma o lugar do silencio no cotidiano dos sujeitos negros, em especial, das mulheres negras. O silêncio - ou silenciamento - ao qual estamos submetidas é construído através das múltiplas facetas que a hegemonia apresenta dentro da nossa vida desde criança, nos adestrando para a mudez.

No silêncio, cada uma de nós desvia o olhar de seus próprios medos - medo do desprezo, da censura, do julgamento, ou do reconhecimento, do desafio, do aniquilamento. Mas antes de mais nada acredito que tememos a visibilidade, sem a qual, entretanto, não podemos viver, não podemos viver verdadeiramente. Neste país em que a diferença racial cria uma constante, ainda que não seja explícita, distorção da visão, nós mulheres Negras temos sido visíveis por um lado, enquanto que por outro nos fizeram invisíveis pela despersonalização do racismo. (LORDE, 1977, p. 42).

Dos muitos momentos em que estive presente na instituição a qual me refiro ao longo destas análises, um deles em especial se destaca nas minhas memórias. Tal cena foi tão marcante na minha experiência de estágio que a mantenho pungente em meus pensamentos, e mal preciso recorrer ao meu diário de campo para recontá-las, em seus mais preciosos detalhes. Esta diz sobre aqueles minutos, que parecem ter durado horas, aqueles que permanecem ecoando em sua cabeça por dias, semanas... Que dizem de rasgos muito profundos em lembranças da minha própria vivência enquanto ser social. Não é de forma alguma uma experiência pessoal, e não ousarei dizer em momento algum que qualquer perspectiva que eu traga seja fruto de uma esfera "pessoal", porque o pessoal não existe. A esfera pessoal diz respeito a algo que é somente seu, que é independente do outro, como se fosse possível viver em sociedade sem depender de um alguém.

Os processos de subjetivação (...), não são centrados em agentes individuais (no funcionamento de instâncias psíquicas, egoicas, microssociais), nem em agentes grupais. Esses processos são duplamente descentrados. Implicam o funcionamento de máquinas de expressão que podem ser de natureza extrapessoal, extraindividual (sistemas maquínicos, econômicos, sociais, tecnológicos, icônicos, ecológicos, etológicos, de mídia, enfim, sistemas que não são imediatamente antropológicos), quanto de natureza infra-humana, infrapsíquica, infrapessoal (sistemas de percepção, de sensibilidade, de afeto, de desejo, de representação, de imagens, de valor, modos de memorização e de produção ideia, sistemas de inibição e de automatismos, sistemas corporais, orgânicos, biológicos, fisiológicos, etc.). (GUATTARI; ROLNIK, 1986, p. 31 apud SOARES, 2016, p. 119).

Nós temos muitas esferas em vida que dizem mais sobre nós, e outras que dizem mais sobre o mundo, mas nenhuma delas representa tanto a totalidade de um sistema capital que reduz sua vida e quem você é a um único indivíduo quanto a suposta experiência pessoal. Deixe-a de lado.

Para a construção deste relato lanço mão do conceito de personagem. Ao ocultar simplesmente nomes ou trocá-los por letras compreendi que deixaria uma lacuna, um 
obstáculo ao nascimento de um corpo nas minhas análises. Por outro lado, a escolha por apontar nomes surge nesse caso como um caminho intrínseco à possibilidade de fadar sujeitos, e em função disto aposto na construção de personagens para além das pessoas em si: O personagem representa um traço característico presente em muitos outros sujeitos ultrapassando aqueles que se fazem presentes na cena.

Enquanto personagem de si mesmo, o personagem conceitual se constitui a partir dos traços existenciais pinçados de seus respectivos modos de vida. $\mathrm{O}$ que requer pensar nos agenciamentos potentes que tornam um enunciado, por mais individual que seja, em uma enunciação coletiva. (SILVEIRA, 2013, p. 114).

Dito isso, apresento a vocês minhas duas companheiras: Isabel e Amada. Tanto Isabel quanto Amada surgem nestes espaços com o pressuposto da boa intenção: Elas desejam ajudar os jovens que ali encontravam-se em cárcere. Isabel é um corpo já moldado pela clínica experiente e já banhado em teorias -, e tal como a princesa busca libertar aqueles que desconhece, uma através do papel e a outra, através das ferramentas que a psicologia oferece. Amada possui, assim como eu, pouquíssima experiência neste campo. Ambas não conhecem o lugar da pele, aquele que apresentei ao longo destes escritos - são pessoas brancas, com experiências diferentes especialmente no que diz respeito ao território. Isabel é moradora de um condomínio, possui carro, duas pós-graduações em instituições privadas e faz atendimentos em seu consultório na área nobre da cidade, tudo isso pouquíssimo tempo após terminar sua graduação. Ela conseguiu em um caso especial, desconstruir toda uma subjetividade marcada pelo tráfico de um modo bastante louvável, valendo-se de determinado escopo teórico que revelou-se outrora bastante eficaz, especialmente em relação aos pacientes que atendia em seu consultório particular. Mas infelizmente, nem todas as teorias, tanto de Isabel quanto de Amada, conseguiriam dar conta do algo que faltava a elas, o que tenho explicitado ao longo dos escritos. Para além de ser negra ou não, o ponto chave desta intervenção esta na capacidade de perceber o quanto determinadas estruturas as atravessam ainda que já conscientes de sua existência no mundo de uma maneira geral.

Era vinte de agosto, ano 2018. Mais uma vez encontrava-me com minha equipe dentro de uma sala, quatro paredes, ao longo de uma tarde para dispor da nossa escuta às questões de alguns dos jovens da instituição. Tínhamos nossa própria lista com os nomes dos internos que atendíamos naquele período, que um a um vai sendo solicitado e vem a nosso encontro. Até que chega a vez do Josué ${ }^{13}$.

Josué era um jovem de uma cidade vizinha, mais ao norte do estado. Foi preso por tráfico e homicídio. Ingressou no comércio de drogas ilícitas aos 13 anos, e até o momento em que foi preso, ocupava um cargo alto no próprio território: acima dele, encontrava-se somente o

\footnotetext{
${ }^{13}$ Nome fictício.
} 


\section{Revista Docência e Cibercultura}

chefe. Possuía um filho e também um advogado particular - diferente dos outros meninos, que eram representados por defensores públicos. Gostaria de salientar a cor da pele de Josué: ele não se entendia enquanto negro. Sua pele era clara. Outro ponto sobre Josué é que ele foi o primeiro jovem que atendi sozinha. Na ocasião, a nossa Isabel não pode estar presente, e a equipe desfalcada precisou se dividir para dar conta da demanda que chegou. Eu e Amada nos separamos, e aquela foi a primeira vez que Josué teve contato com a equipe, no momento, através de mim. Ele me contou sua história, e depois repetiu para as minhas colegas nos encontros seguintes. Josué se tornou uma referência para mim porque foi a primeira e única vez em que a minha perspectiva acerca da história de alguém foi totalmente considerada, afinal não havia ninguém ao meu lado para quem eu devesse olhar e receber consentimento. A história de Josué atravessava a cada pessoa do trio de maneira ímpar, preciso dizer, e eu conhecia bastante estes posicionamentos. Agora preciso dizer do meu.

Josué entra na sala já sem nenhum desejo de esconder sua inquietação. Seu corpo demonstrava a euforia de quem precisava falar. "Mataram um amigo meu. Minha mãe veio me contar na última visita", ele revela, sem nem perguntarmos, nos primeiros minutos da sessão. "Quando eu sair eu vou atrás de quem matou ele, eu vou matar". E o que segue após essa frase é ponto chave das minhas análises.

Dizer que ao deixar a cadeia irá procurar o assassino de seu amigo e executá-lo é a afirmativa de um retorno ao movimento ilícito o qual Josué estava inscrito e que em momento algum concordou em abandonar. Conseguir uma arma, recuperar o prestígio no seu território, é sobre um retorno ao espaço social que jamais foi negado. Na verdade, em todas as vezes que nos encontramos, nunca foi desejo de Josué deixar de fazer parte do tráfico de drogas e seus planos após sua saída sempre envolviam retomar o cargo que ocupava, ganhar dinheiro para mandar ao filho e para ajudar a mãe. Essas eram as metas possíveis, palpáveis.

Nesse dia em especial, o posicionamento se manteve. Josué não queria deixar o tráfico. O suposto consenso entre o nosso trio era de que não tentávamos mudar a vida de ninguém, especialmente baseando-se no que é certo ou errado, mas que tentaríamos apresentar aos jovens saídas que não o fariam voltar para a cadeia ou morrer, e nesse contexto, é sobre não retornar para a atividade que oferece os maiores riscos de mandar qualquer um deles tanto para a jaula quanto para a cova. Em todos os outros encontros esse era o princípio da intervenção possível, e como em outros momentos, nesse dia Josué contra argumentava com respostas que para ele eram plausíveis e não se deixava atravessar de forma alguma quando minhas companheiras expuseram as questões que nasciam junto da sua obstinação em matar alguém.

Princípio do argumento: Você vai morrer. 
Entre falas que se revezavam, o jogo de argumentar e contra argumentar vai ganhando energia, exaltando os ânimos, e junto disto surgem novas perspectivas. "Você poderia sair do tráfico e ir trabalhar como padeiro! Assim você não vai ser preso e também não vai morrer!". Josué continua a relutar e justifica dizendo que não, que poderia ser morto enquanto trabalha, "mas você pode morrer trabalhando no tráfico também" é a resposta.

Princípio do argumento: Há outros empregos.

Depois disso me pareceu que a intervenção desceu ladeira abaixo. Os argumentos foram ficando cada vez mais rasos, e a conversa foi se aproximando de uma discussão infantil, onde ambos relutavam em dar o braço a torcer em um debate sem rumo. $\mathrm{O}$ fato que desencadeou a inquietação de Josué - a morte do amigo - foi pouco a pouco sendo deixado de lado, relembrado vez ou outra como "É assim que se resolvem os conflitos? É só matando que dá pra resolver?", mas nunca enquanto a dor de uma perda, ou como modo de reagir frente ao luto. A impressão que tenho é que Josué não queria escutar naquele dia. Ele só queria falar. $\mathrm{E}$ toda aquela postura rígida apresentada por ele ao longo de todos os nossos encontros que poderia ser dissolvida - ou não - no único momento em que ele baixou a guarda permitindo ser acolhido, nós não soubemos encarar e ele se tornara uma fortaleza ainda mais impenetrável. Josué sabia que nós não iriamos entender. E seu argumento se tornou "Porque eu sou assim, porque nasci assim".

Por fim, minhas companheiras expuseram sua insatisfação com a manutenção dessa postura inquebrável de bandido que o Josué mantivera encontro após encontro, sem admitir uma mínima entrada sequer. "Por que você vem então?". É o questionamento. Afinal, se não há nada que possamos fazer, não há nada que possamos fazer. "Acho que o verdadeiro Josué está preso, embaixo de várias correntes, e que vai ser difícil chegar até ele", é o que ele nos diz. A sessão é encerrada pouquíssimos minutos após ter sido iniciada e ele deixa a sala. A intervenção é um sucesso. Para quem?

Há muitas coisas que me incomodam nessa cena, mas gostaria de dizer do que se passa depois dela antes esmiuçá-la. É consenso entre a equipe que deveríamos deixar Josué um tempo sem atendimento para ver como ele reagiria, se isso fará alguma falta no dia-a-dia dele. Essa foi a última vez que tive a oportunidade de "conversar" com ele. Para Isabel e Amada foi um encontro cansativo. Para mim, foi como peneirar vento. O que aconteceu? Algo aconteceu? Só se foi em mim.

No meu diário de campo, quando me refiro a este dia, escrevo o seguinte: "Josué continua inquebrável. Ainda empresário do tráfico, após muitos embates e implicações, ele diz que o Josué está embaixo de muitas correntes, e que será difícil tirar. Isabel encerra.” 
Na minha cabeça, aquela cena foi trágica. No meu diário é assim que eu a descrevo. Dentre tantos relatos aos quais dediquei parágrafos imensos, quando me refiro a esse dia tão marcante e específico eu escrevo três linhas.

O posicionamento de Josué ao longo da cena, tal como o posicionamento de minha equipe naquela experiência de clínica psicológica remontava não somente a sua subjetividade, mas a toda uma complexa rede vinculação de sujeitos via território e classe social que cria homens e mulheres com questões bastante parecidas - e formas de enxergar o mundo bastante parecidas. De certo, é possível dizer que toda essa rede complexa é capaz de criar subjetividades específicas voltadas para aqueles que compartilham desta mesma rede.

Falar da história de um jovem favelado é falar sobre a história de uma criança favelada. De fato, Ariès (1981) ao expor em seu livro a "História da Infância" como o conceito de infante foi construído ao longo da história da humanidade, nos permite compreender a existência de infâncias distintas, às quais o Estado insiste em separar e nós, enquanto sociedade civil, insistimos em reforçar quando apostamos no senso comum. A mãe burguesa é aquela responsável por educar bons filhos, passível de confiança. A mãe miserável é a nutriz simplesmente, a qual o Estado reserva vigilância constante, cujos filhos já estão determinados à vadiagem, tendo sua sina somente alterada quando ocorre a intervenção externa. Que crianças criamos? E que jovens se tornarão? Neste cenário, observamos a ascensão das infâncias em perigo - aquelas não alcançadas pelas políticas de assistência do poder público e as perigosas - os delinquentes, produto também da omissão estatal no que tange aos direitos da criança (SCHEINVAR, 2002) - ambas presentes nos infantes favelados.

A criança da Idade Média, do início da Idade Moderna e por muito tempo nas classes populares ingressava no mundo dos adultos tão logo fosse capaz de dar conta de si sem o apoio de sua mãe ou ama, por volta dos sete anos de idade. A família cumpria uma função puramente materialista, voltada para os nomes e bens (ARIÈS, 1981).

\footnotetext{
O grande acontecimento foi, portanto, o reaparecimento no início dos tempos modernos da preocupação com a educação. Este interesse animou certo número de eclesiásticos e juristas ainda raros no século $\mathrm{XV}$, mas cada vez mais numerosos $\mathrm{e}$ influentes nos séculos XVI e XVII, quando se confundiram com partidários da reforma religiosa. Pois eles eram antes de tudo moralistas, mais do que humanistas: (...) Esses reformadores, esses moralistas (...) lutaram com determinação contra anarquia (ou o que lhes parecia então ser anarquia) da sociedade medieval. (...) Iniciou-se então uma verdadeira moralização da sociedade: o aspecto moral da religião pouco a pouco começou a prevalecer na prática sobre o aspecto sacro ou escatológico. (...) Constatamos sua influência sobre a história da escola, a transformação da escola livre em colégio vigiado. (ARIÈS, 1981, p. 276).
}

O surgimento de uma preocupação pública em relação à educação das crianças instalou-se assim no seio da sociedade, tirando a família do lugar do privado, possibilitando o 
desenvolvimento do sentimento de família moderna, resultado das produções afetivas e do cuidado destinado às crianças. (ARIÈS, 1981). "A aprendizagem tradicional foi substituída pela escola, uma escola transformada, instrumento de disciplina severa, protegida pela justiça e pela política" (Idem, p. 277).

Ao observar o contexto onde surgem as infâncias, especialmente ao comparar o lugar do infante na civilização medieval e na sociedade moderna, é possível demonstrar que o nascimento do conceito de criança a ser protegida tal qual observamos na atualidade é fruto de uma preocupação política direcionada ao controle moral, tanto das crianças quanto das famílias, especialmente no que diz respeito às famílias pobres (DONZELOT, 1980), perpassando o contexto disciplinar da instituição escolar.

A infância na favela ou em qualquer outro território exposto a miséria, a cujos sujeitos se nega gozar de qualquer aspecto presente em uma sociedade democrática de direito tende a ser mais curta, com meninos e meninas assumindo responsabilidades ligadas a afazeres domésticos e de cuidado, e sendo frequentemente adultizados através de olhares, que erotizam os corpos femininos e adestram corpos masculinos na persona do sujeito-homem. Dessa forma, "a subjetividade do sujeito-homem transparece menos como um problema moral e mais como o fruto de um processo político que se desenrola sob um cenário de falta de liberdades individuais e coletivas" (LYRA, 2013, p. 96).

Pode-se afirmar que "a proteção da infância, nesse sentido, não está completa, pois no morro, assim como no antigo regime, um adulto submisso é uma criança e uma criança independente é um sujeito-homem" (LYRA, 2013, p.96), o que compreende o olhar destes jovens sujeitoshomem acerca da população adulta local, submissa a um trabalho exploratório e vendendo sua mão-de-obra por um rendimento que não garante a subsistência em uma comunidade pobre.

Um elemento comum a todas as infâncias - e que talvez facilite a nossa leitura acerca desta cena - é a escola. Os jovens se encontram na escola. Não importa se é uma escola periférica, degradada e abandonada pelo poder público ou a de primeira linha, de onde saem os médicos e engenheiros: É onde as juventudes acontecem. Mesmo envoltas por questões sociais diferentes, é sobre deixar de ser criança e passa a ser adulto - a adolescência. Diferente do que diz o senso comum, o adolescente traficante e baderneiro também tem a escola como uma referência na vida. É um espaço que participa da construção da sua subjetividade tanto quanto a de qualquer outro adolescente. Talvez a diferença esteja na criminalização da pobreza ao qual encontra-se subjugado, afinal, nunca houve antes na história das escolas burguesas um adolescente branco problemático?

(...) fica clara a importância da escola como um espaço mediador de mundos, isto é, entre a favela e a cidade. $\mathrm{O}$ abandono da escola é mobilizado por esse menino com um peso simbólico tremendo. A diretora, os cursos, a vida regrada e cheia de 
perspectivas própria da instituição, tudo isso se perdeu como se a chance de uma vida 'normal' em si também tivesse sido perdida pelo jovem. (LYRA, 2013, p. 97).

No entanto, quando a realidade convoca, a escola ganha uma representação diferente para estes sujeitos. Ocorre de fato em muitos casos certa frustração dos meninos em relação à escola e a impossibilidade de obter sua autonomia por via dela. Muitos deles compreendem a importância desta instituição, mas reconhecem também que só é um caminho de sucesso para aqueles que possuem uma boa rede de apoio familiar, principalmente financeira (LYRA, 2013). Não por acaso, durante algum período, muitos conciliam as atividades ilícitas e seus estudos, antes de abandonar este espaço. É importante frisar que não somente esta frustração com a escola é fator determinante para a escolha pelo tráfico, mas sim "os processos, em suas muitas facetas, que determinam as escolhas feitas pelos jovens” (LYRA, 2013, p. 97) que é o que está em jogo.

Quando o jovem abandona a escola ele abandona este mediador entre os dois mundos, do morro e do asfalto, e passa a viver apenas no mundo em que conhece, nos limites de sua comunidade ou entre uma comunidade e outra, convivendo com seus pares, envolvidos no tráfico ou não. No morro, as hierarquias de idade são subvertidas, o jovem está submetido a outros padrões de ascensão e interação social, muito mais palpáveis que as do contexto escolar. "O jovem não despreza o trabalho e a escola, tampouco os trabalhadores e estudantes, apenas substitui os mecanismos sociais de ascensão disponíveis anteriormente por outros compatíveis com a realidade exclusiva do morro na qual sempre foi condenado a viver" (LYRA P. 99).

(...) a vida na favela concentra praticamente todas as referências individuais e coletivas do jovem sujeito-homem. Nesse sentido, não só a valorização do cria, como elemento nativo da comunidade, mas também as visitas que o jovem faz a outros morros aliados, a serviço ou por lazer, tornam claro o entendimento de que o "asfalto" ocupa um lugar apenas de acessório em suas trocas sociais. A despeito disso, muitos pesquisadores desprezam esse dado e procuram caracterizar o menino sujeito-homem a partir de padrões e expectativas que não dialogam diretamente com a vida na favela, mas que têm como ponto primordial de comparação as crenças e temores do próprio 'asfalto'. Assim, alguns investigadores justificarão a adesão a partir de temas como o 'desejo de ter a vida dos ricos', 'humilhar quem tem mais', 'ganhar notoriedade', 'ganhar dinheiro fácil', 'recusa ao trabalho humilde', 'revolta' - elementos que ganham sentido apenas se vislumbrados à luz de nossa própria dinâmica social, isto é, a vida da cidade, e não da favela. (LYRA, 2013, p. 100).

Para a vida no asfalto, os jovens reconhecem seu poder nulo de existência, ao passo que no morro podem ser reconhecidos e respeitados pelos seus feitos, tanto entre seus pares, quanto entre as mulheres e pelos moradores. É ali que a vida faz sentido, que eles são reconhecidamente algo. Falar com eles na perspectiva do asfalto, tentar vislumbrar nestes sujeitos questões pertinentes somente a nossa perspectiva de vida diante disso soa como um esforço válido, porém fraco. A possiblidade de morte, de fazer uma faculdade, e entre outras 
questões nesse momento fazem outro sentido, e talvez não sejam provocações que movam este alguém. É cavar raso demais.

Em seu livro, Diogo Lyra (2013, p.104) escreve: “É preciso que o menino sujeito-homem seja aprovado por seus colegas e patrão, seja querido, temido e respeitado por sua comunidade, e que seja, inclusive lembrado como uma peça importante da engrenagem". Esta frase para mim é crucial na leitura de Josué. Em certa perspectiva a lealdade cega, o desprezo à morte e o ódio ao inimigo cujo rosto nem se conhece remonta a uma lavagem cerebral tão intensa que beira a insanidade, mas o laço que vincula este jovem a essas questões, apesar de parecer tão frouxo e fácil de ser desfeito, possui raízes profundas de mais, e tentar desmontá-las é também desmontar um sujeito. E este é um processo que não se resolve por completo em algumas semanas de terapia. E o pior é que Josué não era de mentir, tampouco de fingir. Talvez o que mais incomodava era o fato dele ser sincero demais, e confrontar nossa intervenção com um tremendo: "Não. Não vai funcionar".

Não é difícil deduzir porque é tão importante o conflito entre os comandos para esses jovens que se engajam no crime e cantam em prosa e verso sua adesão ao tráfico. Um comando precisa do grupo inimigo e das guerras constantes para construir e intensificar sua coesão interna. Compreende-se a obsessão guerreira, fartamente registrada no funk do mal. A disposição belicista coexiste com a exaltação da fidelidade ao grupo criminoso. São duas faces da mesma moeda. Ambas jogam água no mesmo moinho: o reforço do sentimento gregário dos jovens. Daí o elogio a lealdade, que se encontra em quase todas as músicas, ainda que geralmente travestido em crítica à traição. Os meninos reverenciam o gregarismo, a lealdade e se identificam por pertencerem a uma coletividade, não importa a cor e o nome do comando. Ídolos e pais simbólicos são evocados. O tráfico é a única rede de apoio mútuo acessível para muitos jovens. Portanto, mesmo com o sabor amargo da nossa falência como sociedade e civilização, ainda há razão para acreditar em mudanças profundas, se não jogarmos o jogo do ódio e da destruição, com sua linguagem arrogante. (LYRA, 2013, p. 144).

Josué não é pulsão de morte. Josué é uma vida distinta da sua. É a certeza de que há muitas opções e poucas chances, e que dessas chances você precisa escolher entre aumentar o tempo de sobrevida ou viver seu gozo.

Em 2018 a ONG Observatório das Favelas divulgou dados relacionados a uma pesquisa que procurava comparar o perfil dos jovens de instituições para cumprimento de medida socioeducativa nos momentos antes e depois da implantação das Unidades de Polícia Pacificadora em 2008. A pesquisa revelou que dos jovens entrevistados, 64,45 deles viviam nas favelas cariocas desde o nascimento, $30,7 \%$ reside com a mãe, $24,5 \%$ com cônjuge e apenas $10,8 \%$ com ambos os pais. O trabalho demonstra ainda uma prevalência de famílias numerosas e matriarcais. Em 50,2\% dos casos a mãe foi citada como principal responsável pela criação do jovem, e o pai aparece em apenas 1,5\% dos relatos. Tais arranjos de família seguem o padrão apresentado pelo IBGE para a população geral. O mesmo estudo expõe que 
$66,3 \%$ dos entrevistados informaram já ter desenvolvido algum tipo de trabalho formal antes de ingressar no comércio ilícito de drogas, geralmente em setores com rendimentos muito baixos. $62,1 \%$ recorreram ao varejo de drogas para ajudar a família. 51,7\% dos entrevistados afirmaram receber entre $\mathrm{R} \$ 1.000$ e $\mathrm{R} \$ 3.000$ desenvolvendo esta atividade. Em fevereiro de 2019 a ONG Redes da Maré divulgou o boletim "Direito à Segurança Pública na Maré", um documento que traz um estudo acerca das violações aos direitos humanos naquela comunidade onde revela que a expectativa de vida no Conjunto de favelas da Maré é de 74 anos, mas que apesar disso, a média de idade dos moradores que morrem no morro é de 24 anos. Apresento esses dados para despertar nos meus leitores os seguintes questionamentos: O que pretendemos, de fato, quando nos direcionamos à jovens como Josué? E o que temos em mente? Estes números estão disponíveis nas mais diversas plataformas a quem se propõe a procurar. Mas os compreendemos de fato?

\section{CONCLUSÃO}

Se eu me propus a fazer um relato de experiência, então está feito. Eu expus a minha experiência, e os meus referenciais. Meus pontos de vistas e como eu analiso cada um deles. Analise sua experiência, relate sua experiência. Está feito.

Não me atrevo de forma alguma com esse trabalho apontar dedos em caras. Dizer-me acima de qualquer um. A minha intenção é oferecer uma perspectiva. Um ponto de vista que foi negado por 500 anos antes de mim e depois. Por 500 anos antes de mim outros tentaram oferecer esta perspectiva, e por 500 anos depois ainda tentarão. Estou fazendo a minha parte.

A pluralidade de questões que suscitam em minhas análises diz particularmente de um racismo estrutural e das desigualdades sociais provenientes dele. De fato, expor todos esses atravessamentos é demonstrar que aquilo que une pobreza, negritude e violência em um único corpo nada mais é do que uma cultura dominante, que por excelência é branca. Toda a construção hierárquica que constitui o território brasileiro enquanto nação se pautou nos pressupostos colonialistas, que para além de invadir terras alheias, revela-se uma estratégia de dominação social contra um povo em específico.

O que é colonizar? Arantes (2011) ao analisar as ideias de Sartre sobre o racismo e sua amizade com Fanon, aponta que os processos subjetivos que acontecem no caso do colonialismo e do racismo se diferenciam demasiadamente da alienação do proletariado, pois no caso do colonizado ocorre uma desumanização, opressão e violência colonial (2011, p. 300). O aculturamento é uma das técnicas de dominação do colonizador, que exige que o colono esqueça-se de suas tradições, crenças e costumes, A língua imposta é outra força de dominação violenta, pois deve esquecer sua língua e aprender a língua do colonizador; esta é a única oficial nesta relação. O trabalho forçado extenuante acaba por desabar qualquer integração possível, ainda 
no nível subjetivo, do mesmo modo que a tortura pode levar qualquer ser humano a se perder psiquicamente; são violências que atuam como ataques à saúde mental. A ideia é de que o escravo torne-se um ser a esmo, inexistente, não há o para-si, ele é destruído. (MAIA, ZAMORA \& BAPTISTA, 2019, p. 109).

Ao expor colonizar como uma gama gigantesca de instrumentos e possibilidades para destituir um povo de si mesmo e junto disso, de suas terras e de sua cultura, como forma de fazê-lo mais dócil e apto à exploração, torno mais evidente o quanto esta cultura colonialista permanece impregnada ainda nos dias atuais, junto dos efeitos produzidos pelos seus ataques mais efetivos - tal como explicitei ao longo de minhas análises.

Em meio a tudo isso, encontra-se a psicologia, o campo de saber que escolhi para a vida. Esta se apresenta também atravessada pelos ideais brancos, quando limita a maior parte de sua produção teórica em conceituações europeias - aquelas não interpeladas pelo racismo de Estado. Como é possível, após entender toda construção de um modelo de sociedade e o quanto isto perpassa as vidas negras, manter a psicologia ereta, alheia e neutra a todas essas questões? A resposta é simples: Não é. E compreendendo isso vemos surgir a cada dia mais estudos voltados para esta problemática. No entanto ainda é pouco: Quando assumimos um currículo majoritariamente branco optamos por nos render a esta lógica também colonialista, entregando a verdade às respectivas mãos brancas. Precisamos de vozes negras, especialmente no que diz respeito ao exercício clínico da psicologia.

$\mathrm{Na}$ realidade da Psicologia clínica brasileira inexiste a preocupação com a experiência de minorias étnicas ou raciais. Martins, Santos e Colosso (2013) encontraram apenas um artigo na área clínica (psicanálise), do total de 42 artigos. A tendência da disciplina é europeizante e arianizante na totalidade de seus modelos. A Psicologia social foi, na década de 1930, pioneira nos estudos de relações raciais (Santos et al., 2012), e é até hoje a área de Psicologia que mais produz nessa temática (Martins et al., 2013). (DAMASCENO E ZANELLO, 2018, p. 453).

Falo de racismo especialmente porque compreendo que os corpos que ocupam estes lugares são negros. E porque a própria organização social marginalizante é produto histórico de uma política de controle social em essência racista. "O racismo no Brasil é um fenômeno ao mesmo tempo presente e negado (ZAMORA, 2012). Os profissionais da saúde mental são incapazes de reconhecer a linguagem, o comportamento e as atitudes racistas internalizadas de seu próprio racismo encoberto.” (DAMASCENO E ZANELLO, 2018, p. 461).

Uma psicologia preta só pode ser construída por profissionais pretos e é este o lugar que precisamos ocupar. A construção deste trabalho revelou o quanto a cor da minha pele e a compreensão de pertencimento a determinado lugar na sociedade em função dela me permitiu uma perspectiva para além do ponto de vista acadêmico disponível, e este processo tornou possível uma busca ampliada, que não se ateve somente aos escritos colonialistas, cujos estudos não poderiam de forma alguma dar conta desta experiência, e me fez procurar ainda 
mais longe - entender o porquê das coisas, suas raízes e assim me colocar frente ao nascimento de uma nova psicologia, que contemple quem sou: Preta!

Quando admito que o exercício da psicologia, até mesmo nas esferas clínicas, não pode deixar de assumir o aspecto político dos sujeitos, aposto no movimento pendular que nos permite acessar a origem macropolítica das questões que se apresentam nas mentes e nos corpos, mas também o que é da ordem micropolítica. Quando um psicólogo se predispõe ao atendimento das demandas psi de um corpo preto é necessário que deixe entrar porta adentro mais do que o sujeito, mas os atravessamentos raciais que também o compõem. $\mathrm{O}$ atendimento pode até ser individual, mas o sujeito não é indivíduo - independente do mundo - e, portanto a clínica não pode ser individualizante. Foi a partir da definição de um povo preto que a hegemonia branca - temendo que a alarmante maioria de pessoas negras tomasse as rédeas dessa nação - construiu um projeto político de exclusão e repressão, e foi com o passar dos séculos, agregando novos inimigos ao grupo alvo. Logo, apesar de hoje encontrarmos enquadrados neste grupo diversas populações, o povo preto em específico sempre ocupou neste lugar. Não é algo novo pra nenhum de nós. E por isso é tão alarmante, e por isso não pode ignorado. "Assim se apresenta a clínica, para nós. O que nos interessa são modos de subjetivação e, neste sentido, importa-nos poder traçar as circunstâncias em que eles se compuseram, que forças se atravessam e que efeitos estão se dando." (BENEVIDES \& PASSOS, 2000, p. 77).

\footnotetext{
As histórias trazidas pelos pacientes não seriam mais apenas conectadas entre si ou com as introduzidas pelo analista, mas também interfaceadas a outros sistemas, outros regimes de signos. (...) não se trata do estabelecimento de sistemas interacionais, mas de diferenças que se introduzem em dimensões da subjetivação, complexificando a situação através da pressão promovida pelos movimentos de desterritorialização. (BENEVIDES \& PASSOS, 2000, p. 78).
}

Além disso, entender a dimensão política do processo clínico nos previne de apostar numa suposta redução de danos em lugares onde não há dano para se reduzir. O psicólogo deve ter cautela ao voltar-se a certos dispositivos para não acabar em busca de uma prisão humanizada, pois tal como demonstro, é necessário compreender que o lugar de cárcere surge em alguns casos de uma construção social idealizada para controle e repressão de uma população determinada antes mesmo de se instaurar punitivista. Reduzir os danos neste contexto não é criar potência, mas contribuir para a docilização dos corpos. É uma prática no lugar do limbo, certamente. Não há caminho fácil.

Segundo René Lourau, fazer uma intervenção significa, dentre outras coisas, "articular lacunas, ver relações onde só se percebiam elementos coerentes e homogêneos, comprovar um problema onde se julgava existirem soluções" (COIMBRA \& NASCIMENTO, 2004b, p.1). Devemos então entender que nossas práticas, sejam como psicólogos ou com cidadãos, devem questionar a naturalidade dos objetos e dos sujeitos que estão no mundo, abrindo espaço para a afirmação das 
diferenças, das multiplicidades de conexões e da produção coletiva de um espaço urbano democrático e da produção de outras formas de ser e estar no mundo (Bicalho, 2005). (BICALHO et. al., 2012, p. 62).

$\mathrm{O}$ que me impulsionou a escrever este trabalho e construir estes estudos, antes de qualquer coisa, foi o meu silêncio. $\mathrm{O}$ que começou com um incômodo acerca desta minha impossibilidade de falar cresceu a ponto de se tornar um tormento tão latente, que fez da minha escrita ao mesmo tempo militante e terapêutica. Era uma ausência de voz que remetia à diversas camadas da malha social: a ideia de que a minha perspectiva, construída pelas experiências com os territórios de pobreza que habitei e pela cor da minha pele, era equivocada porque historicamente, é o que se diz sobre pessoas semelhantes a mim. À minha mãe, minha avó, e a todas que vieram antes delas... Ter que provar ser intelectualmente capaz. Racismo.

(...) O que me dava tanto medo? Questionar e dizer o que pensava podia provocar dor, ou a morte. Mas, todas sofremos de tantas maneiras todo o tempo, sem que por isso a dor diminua ou desapareça. A morte não é mais do que o silêncio final. E pode chegar rapidamente, agora mesmo, mesmo antes de que eu tenha dito o que precisava dizer. (LORDE, 1977, p. 41)

Apesar de ter uma história muito parecida com a dos jovens da referida instituição, nunca tive a oportunidade de dizer isso a eles diretamente. Eu nunca expus que sou filha de uma faxineira igual a eles, que tive um filho aos 17 como eles, que convivi entre pessoas pobres, frequentei bailes funk, perdi amigos em balas perdidas e escondi parentes de perseguições do tráfico, igual a eles. Pude ver pessoas se reinserirem na vida em sociedade após envolveremse no varejo de drogas, e tenho dimensão do quão difícil e delicado esse processo é. Mas eu não tive tempo de contar. Eu imagino que eles tenham percebido que eu era diferente. Minha cor se destacava, minhas roupas, meu jeito de falar. Mas dizer com palavras é diferente. Ficar no dito pelo não dito não é do meu feitio. Mas o não falar foi resultado de um processo. E isso só se torna nítido no presente. Apesar disso fiz da minha escrita um deslocamento possível: A minha capacidade de escrever e de analisar certamente foi produto da minha incapacidade de falar.

Contudo, proponho nestas linhas através deste um relato de experiência que as perspectivas se ampliem e abarquem agora aqueles que compõem uma boa parte dos objetos de estudo da academia - especialmente o contexto social. Segundo a Associação Nacional dos Dirigentes das Instituições de Federais de Ensino Superior - ANDIFES, em 2018 cerca de $70 \%$ dos alunos das universidades federais tinham renda de até um salário mínimo e meio, 39,2\% deles são pardos e $12 \%$ negros, um perfil construído através das políticas de cotas, da qual também sou produto enquanto acadêmica ${ }^{14}$. A população negra e pobre têm ocupado as universidades pouco a pouco, e a construção de um conhecimento atravessado pela subjetivação de quem é

\footnotetext{
${ }^{14}$ Dados obtidos na $5^{\text {a }}$ Pesquisa de Perfil Socioeconômico dos Estudantes das Universidades Federais.
} 
também alvo no complexo jogo de relações estruturais vividas em sociedade torna-se uma feliz consequência, tão inevitável quanto a tomada de consciência deste mesmo povo.

\section{REFERÊNCIAS}

ALAPOLA, Kaique. Negros representam dois terços da população carcerária brasileira. Portal R7, 2017. Disponível em: https://noticias.r7.com/brasil/negros-representam-dois-tercos-da-populacao-carceraria-brasileira08122017. Acesso em: 17 jun. 2019.

ARIES, P. História social da criança e da família. 2. ed. Zahar Editores. Rio de Janeiro, 1981.

BAREMBLITT, Gregorio F.Compêndio de análise institucional e outras correntes: teoria e prática. 5. ed. Instituto Felix Guattari. Belo Horizonte, 2002.

BASSETT, Fernanda. Brasil tem 5,5 milhões de crianças sem pai no registro. Exame, 2013. Disponível em: https://exame.abril.com.br/brasil/brasil-tem-5-5-milhoes-de-criancas-sem-pai-no-registro/. Acesso em: 18 jun. 2019 .

BENELLI, Sílvio José. A Instituição total como agência de produção de subjetividade na sociedade disciplinar. Estudos de Psicologia (campinas), Campinas, v. 21, n. 3, p.237-252, dez. 2004. http://dx.doi.org/10.1590/s0103$\underline{166 \times 2004000300008 .}$

BENEVIDES, Regina. A psicologia e o sistema único de saúde: quais interfaces?. Psicologia \& Sociedade, Porto Alegre, v. 17, n. 2, p.21-25, ago. 2005. http://dx.doi.org/10.1590/s0102-71822005000200004.

BIANCHI, Paula. 9 em cada 10 mortos pela polícia no Rio são negros ou pardos. UOL, 2017. Disponível em: https://noticias.uol.com.br/cotidiano/ultimas-noticias/2017/07/26/rj-9-em-cada-10-mortos-pela-policia-no-riosao-negros-ou-pardos.htm. Acesso em: 17 jun. 2019.

BIANCHI, Paula. Número de mortos pelas polícias no RJ passa de 1.000 em 2017 e já é o maior em quase 10 anos. UOL, 2017. Disponível em: https://noticias.uol.com.br/cotidiano/ultimas-noticias/2017/12/18/numero-demortos-pela-polica-no-rio-ultrapassa-os-1000-e-ja-o-maior-em-quase-10-anos.htm. Acesso em: 17 jun. 2019.

BICALHO, Pedro Paulo Gastalho de; KASTRUP, Virginia; REISHOFFER, Jefferson Cruz. Psicologia e segurança pública: invenção de outras máquinas de guerra. Psicologia \& Sociedade, [s.1.], v. 24, n. 1, p.56-65, 2012. Disponível em: http://www.scielo.br/pdf/psoc/v24n1/07.pdf. Acesso em: 17 jun. 2019.

CASTRO, Flora. Expectativa de vida na Maré é de 74, mas média das mortes é de 24 anos, diz relatório. Brasil de Fato, 2019. Disponível em: https:/www.brasildefato.com.br/2019/02/22/redes-da-mare-lanca-boletimdireito-a-seguranca-publica-na-mare/. Acesso em: 17 jun. 2019.

COIMBRA, C.; RIBEIRO, R.; SILVA, M. Especialista do Juizado e a doutrina de Segurança Nacional. In: NASCIMENTO, Maria Lívia do. (org.) Pivetes: a produção de infâncias desiguais Niterói: Intertexto; Rio de Janeiro: Oficina do Autor. 2002.

COIMBRA, Cecília Maria Bouças; NASCIMENTO, Maria Lívia do. Sobreimplicação: práticas de esvaziamento político? 2004. Disponível em: https://app.uff.br/slab/uploads/texto22.pdf. Acesso em: 17 jun. 2019.

COIMBRA, Cecília. Operação Rio: o mito das classes perigosas: um estudo sobre violência urbana, a mídia impressa e os discursos de segurança pública. Rio de Janeiro, Oficina do Autor. Niterói, Intertexto. 2001. 
CUNHA, Eduardo L. Entre o assujeitamento e a afirmação de si. Cadernos de Psicanálise, SPCRJ, v.18, n.21, p.167-180. 2002. Disponível em: http://ebep.org.br/artigos/2Cunha_-_confissao_spcrj____pdf. Acesso em: 17 jun. 2019.

D’ELIA FILHO, Orlando Zaccone. Acionistas do nada: quem são os traficantes de droga. Rio de Janeiro: Revan, 2007. $2^{a}$ edição abril de 2008.

DAMASCENO, Marizete Gouveia; ZANELLO, Valeska M. Loyola. Saúde Mental e Racismo Contra Negros: Produção Bibliográfica Brasileira dos Últimos Quinze Anos. Psicologia: Ciência e Profissão, Brasília, v. 38, n. 3, p.450-464, set. 2018. http://dx.doi.org/10.1590/1982-37030003262017.

DONZELOT, J. A polícia das famílias. Edições Graal. Rio de Janeiro, 1980.

FÁBIO, André Cabette. O perfil dos traficantes no Rio. E o que os atrai para o crime. NEXO, 2018. Disponível em: https://www.nexojornal.com.br/expresso/2018/08/02/O-perfil-dos-traficantes-no-Rio.-E-o-que-os-atrai-parao-crime. Acesso em: 17 jun. 2019.

GARCIA, Maria Fernanda. Show de horror: até 1958, existiam zoológicos humanos pelo mundo. Observatório do terceiro setor, 2018. Disponível em: https://observatorio3setor.org.br/carrossel/show-de-horror-ate-1958existiam-zoologicos-humanos-pelo-mundo/. Acesso em: 17 jun. 2019.

LORDE, Audre. The Transformation of Silence into Language and Action. In: LORDE, Audre. Sister Outsider: essays and speeches. Crossing Press. Trumansburg, 1984.

LYRA, Diogo. A república dos meninos: juventude, tráfico e virtude. Rio de Janeiro: Mauad X: FAPERJ, 2013.

MAIA, Kenia Soares; ZAMORA, Maria Helena Navas; BAPTISTA, Rachel Fontes. Reflexões sobre o racismo em Campos dos Goytacazes: um olhar existencialista sobre a descolonização. Revista de Psicologia, Fortaleza, v. 10, n. 1, p.105-112, 2019. Disponível em: http://www.periodicos.ufc.br/psicologiaufc/article/view/33680. Acesso em: 17 jun. 2019.

MAIORIA dos alunos das universidades federais tem renda baixa, é parda ou preta e vem de escola pública. O Globo. 2019. Disponível em: https://oglobo.globo.com/sociedade/2019/05/17/582327-maioria-dos-alunos-dasuniversidades-federais-tem-renda-baixa-parda-ou-preta-vem-de-escola-publica. Acesso em 17 jun. 2019.

MBEMBE, Achille. Necropolítica. Arte \& Ensaios: revista do ppgav/eba/ufrj, Rio de Janeiro, n. 32, p.123-151, 2016. Disponível em: https://revistas.ufrj.br/index.php/ae/article/view/8993/7169. Acesso em: 17 jun. 2019.

PASSOS, Eduardo; BARROS, Regina Benevides de. A construção do plano da clínica e o conceito de transdisciplinaridade. Psicologia: Teoria e Pesquisa, Brasília, v. 16, n. 1, p.71-79, abr. 2000. http://dx.doi.org/10.1590/s0102-37722000000100010.

SARAIVA, Adriana. População chega a 205,5 milhões, com menos brancos e mais pardos e pretos. Agência IBGE de Notícias, 2017. Disponível em: https://agenciadenoticias.ibge.gov.br/agencia-noticias/2012-agencia-denoticias/noticias/18282-populacao-chega-a-205-5-milhoes-com-menos-brancos-e-mais-pardos-e-pretos. Acesso em: 18 jun. 2019.

SCHEINVAR, E. Idade e proteção: fundamentos legais para a criminalização da criança e do adolescente e das famílias (pobres). In: NASCIMENTO, Maria Lívia do. (org.) Pivetes: a produção de infâncias desiguais Niterói: Intertexto; Rio de Janeiro: Oficina do Autor. 2002.

SILVA, Alyne Alvarez. Das vidas que não (se) contam: dispositivos de desinstitucionalização da medida de segurança no Pará. 2015. 345 f. Tese (Doutorado em Psicologia Social). Pontifícia Universidade Católica de São 


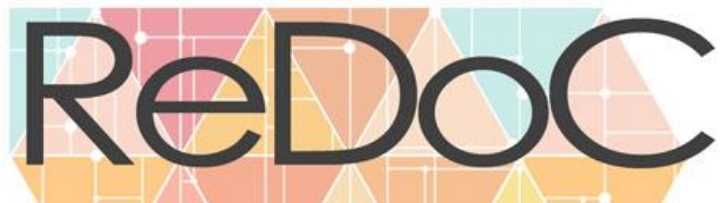

Paulo,

São

Paulo,

\section{Revista Docência e Cibercultura}

https://leto.pucsp.br/bitstream/handle/17130/1/Alyne\%20Alvarez\%20Silva.pdf. Acesso em: 17 jun. 2019.

SILVEIRA, Luana da. Hóspedes do Profeta sem Morada: estudo sobre modos de subjetivação da migração, a partir das experiências de estudantes de pós-graduação participantes de programas de intercâmbio internacional. Tese (doutorado) - Universidade do Estado do Rio de Janeiro, Programa de Pós-Graduação em Psicologia Social. Rio de Janeiro, 2013. Disponível em: http://www.bdtd.uerj.br/tde_busca/arquivo.php?codArquivo=6109. Acesso em: 17 jun. 2019.

SOARES, Fabio Montalvão. A produção de subjetividades no contexto do capitalismo contemporâneo: Guattari e Negri. Fractal: Revista de Psicologia, Rio de Janeiro, v. 28, n. 1, p.118-126, abr. 2016. Http://dx.doi.org/10.1590/1984-0292/1170.

SOUZA, Tadeu de Paula. A norma de abstinência e o dispositivo "drogas": direitos universais em territórios marginais de produção de saúde (perspectivas da redução de danos). 2013. 355 p. Tese (doutorado) Universidade Estadual de Campinas, Faculdade de Ciências Médicas, Campinas, SP. Disponível em: http://www.repositorio.unicamp.br/handle/REPOSIP/312021. Acesso em: 17 jun. 2019.

VIEIRA, Isabela. IBGE: negros são 17\% dos mais ricos e três quartos da população mais pobre. Agência Brasil, 2016. Disponível em: http://agenciabrasil.ebc.com.br/geral/noticia/2016-12/ibge-negros-sao-17-dos-mais-ricose-tres-quartos-da-populacao-mais-pobre. Acesso em: 18 jun. 2019.

ZAMBENEDETTI, Gustavo; SILVA, Rosane Azevedo Neves da. Cartografia e genealogia: aproximações possíveis para a pesquisa em psicologia social. Psicologia \& Sociedade, [s.1.], v. 23, n. 3, p.454-463, dez. 2011. http://dx.doi.org/10.1590/s0102-71822011000300002. 